\title{
Correspondence
}

\section{The dangers of the supervision register}

Sir: The Secretary of State for Health announced in December 1993 a requirement that mental health providers establish and maintain supervision registers which identify those people with a severe mental lliness, or diagnosed personality disorder who may be of significant risk to themselves or others. In February 1994 document HSG (94) 5 was sent out which outlines the requirements of the supervision register.

I am concerned about certain aspects of the supervision register which I have outlined under three headings.

\section{Ethical issues}

I am concerned about the effect of the supervision register on the role of the psychiatrist. The psychiatrist will now become an agent of the state with powers to put patients on a register which will be kept on a computer databank. There is a danger that this list could be used for other purposes. This clearly occurred in a case of HIV testing where patients applying for work, life insurance or mortgages were asked if they had been tested. It is likely that applicants will now be asked if they have ever been placed on a supervision register.

Psychiatrists will have to inform patients that they will be placed on the register. There is no official right of appeal as with the Mental Health Act. Just think what damage this will do to the doctor/patient relationship. Patients will hardly be likely to come forward and confide their suicidal and perhaps homicidal thoughts, and place their trust in their doctor. In some cases psychiatrists will be placed at risk due to the possibility of reprisals by patients with paranoid symptoms or sociopathic traits.

\section{Practical problems}

Setting up the supervision register will involve a tremendous amount of extra work to an already over-stretched service. Special review meetings will need to be set up, there will be extra paper work and patients will need to be informed. The document states that "patients should be informed orally and in writing when they are put on a supervision register and broadly told why they have been placed on it, how the information on the register will be used, to whom it may be disclosed and the mechanisms for review". Additional multidisciplinary review meetings will have to be set up and the patient will have the right to request a removal from the register, necessitating further review meetings by the clinical team.

\section{Funding issues}

Where are the extra professionals and services required to set up and police the register? Where are the additional community psychiatric nurses, social workers and psychiatrists? Where is the money to provide them? Across the country trusts are reducing funding for mental health services, and increasing demands are being made on a contracting service. What will actually happen in regard to the supervision register is that money will be moved away from existing clinical services in order to run the register.

Finally, I would argue that there is now a suitable and adequate method of supervising and monitoring patients at risk, the Care Programme Approach. The aim of the Care Programme Approach is to work together with patients with their agreement. The supervision register adds a different dimension to this approach which is more to do with responsibility and attaching blame rather than benefiting patient care.

R. D. ADAMS, Bootham Park Hospttal, York YO3 7BY

(See pages 385-388-ed.)

\section{Implications of the Calman Report}

Sir: I welcome the debate which is occurring about the implications of the Chief Medical Offcer's (Calman) Report on Specialist Training.

However, I think that Dr Kisely is misleading your readership in suggesting that "the Colleges of other medical specialties in Britain may soon require only five to six years of training" (Psychiatric Bulletin, May 1994, 18, 309). My understanding of the work which is in hand in other medical Royal Colleges is that five to six years of specialist training is being considered, following a period of general professional/basic specialist training of one to two years.

In relation to the stipulation of the Royal Australian \& New Zealand College of Psychiatrists' requirement for five years training in 